Volume 10 - $2020 \mid$ n. 32

\title{
Acompanhamento Público dos Investimentos em Educação em Viçosa/MG ${ }^{1}$
}

\author{
Renata Martins Pena \\ Cristiane Aparecida Baquim \\ Natália Rigueira Fernandes \\ Henrique Pinto Gomide \\ Universidade Federal de Viçosa (UFV), Viçosa/MG - Brasil
}

\section{Resumo}

O trabalho analisa a atuação dos Conselhos (Municipal de Educação, do FUNDEB e de Políticas Públicas) em suas atividades de acompanhamento e controle público dos investimentos em educação em Viçosa/MG, a partir da abordagem qualitativa, com a análise das atas, das pautas e observação de 15 reuniões dos Conselhos realizadas no ano de 2018. Identificamos uma baixa participação da comunidade nas reuniões do conselho. Os seguintes temas foram encontrados nas atas e pautas disponíveis: aplicação dos recursos do FUNDEB, transporte escolar, denúncias de uso irregular da subvenção, alocação de recursos para as creches conveniadas. Com base nos resultados encontrados, concluímos que o sistema de educação deve desenvolver novas estratégias para aumentar a participação dos conselheiros, sugerindo a profissionalização e treinamento dos conselheiros para garantir que a gestão democrática dos recursos públicos possa ser garantida.

Palavras-chave: Conselhos. Gestão Democrática. Acompanhamento Público. Financiamento.

\section{Public Monitoring of Investments in Education in Viçosa - Minas}

\section{Gerais}

\section{Abstract}

The work analyzes the performance of the Councils (Municipal of Education, FUNDEB and Public Policy) in their activities of monitoring and public control of investments in education in Viçosa / MG, from the qualitative approach, with the analysis of the minutes, agendas, guidelines and observation of 15 Council meetings held in 2018. We have identified low community participation in board meetings. The following topics were found in the minutes and guidelines available: application of FUNDEB resources, school transportation, complaints of irregular use of the subsidy, allocation of resources to the accredited daycare centers. Based on the results found, we concluded that the education system should develop new strategies to increase the participation of councilors, suggesting the professionalization and training of councilors to ensure that democratic management of public resources can be guaranteed.

Keywords: Public councils. Democratic management. Public monitoring. Education funding.

1 Este estudo foi financiado pela Fundação de Amparo Pesquisa do Estado de Minas Gerais - FAPEMIG. 
Acompanhamento Público dos Investimentos em Educação em Viçosa/MG

\section{Introdução}

Entender como ocorre o financiamento da educação no Brasil requer uma compreensão ampliada sobre a arrecadação de tributos, repasses constitucionais, fundos de participação, percentuais mínimos de aplicação, dentre tantos outros elementos que tornam esse um campo de difícil acesso e de pouca mobilização para os munícipes.

Os recursos destinados à educação, segundo Duarte e Faria (2010), são arrecadados, em sua maioria, através de impostos que podem ser afetados pela economia e pela sonegação fiscal. Esses recursos levantados são vinculados por força de lei e distribuídos entre estados e municípios, cabendo a estes garantirem o acesso, a permanência e a qualidade social da educação. E, para efetivar o controle social dos gastos com a educação, instituíram-se os Conselhos no âmbito dos municípios. Nessa pesquisa, a partir da observação dos Conselhos (Conselho Municipal de Educação, do FUNDEB e de Políticas Públicas), foi possível conhecer a aplicação de recursos e como tais conselhos atuam na fiscalização do repasse, visando garantir que seja prestado o atendimento de qualidade a toda a população em idade escolar.

Para tanto, iniciamos nossa análise pela compreensão do papel do município na oferta de educação pública em seu nível de atuação, a partir dos processos de municipalização e descentralização ocorridos no Brasil.

\section{Municipalização da Educação}

As políticas educacionais, que tiveram lugar na agenda pública brasileira a partir do final dos anos 1980 e início de 1990, foram marcadas por princípios da descentralização, da democratização e da participação. Assim, o estudo das políticas educacionais requer um olhar atento aos processos de redistribuição das responsabilidades das esferas de poder através da descentralização no âmbito da política social. No que concerne à oferta de serviços educacionais, traduz-se na descentralização da gestão da educação e da municipalização do ensino. O Brasil observou, a partir dos anos 1990, uma ampliação no processo de descentralização da administração e da burocracia estatal para os estados e municípios, a partir do reconhecimento histórico feito pela Constituição Federal (CF) de 1988 da autonomia dos municípios e do ascenso destes como entes federativos. Também essa Carta Magna assegura o princípio da gestão democrática como o balizador principal da administração dos sistemas de ensino, tanto no âmbito do município quanto da questão da escola.

A partir desse reconhecimento, os municípios passaram a participar mais ativamente das ações no campo das políticas educacionais, que delimitaram novas competências e incumbências para este ente federativo, definiram restrições e regularam o financiamento. Tais políticas vieram acompanhadas de um processo de municipalização das escolas que nunca havia sido observado na história da educação do País.

Sabe-se que a descentralização é um mecanismo utilizado pelos organismos multilaterais (e.g. Banco Mundial e Fundo Monetário Internacional) para a reorganização do Estado e da educação. A alocação de recursos para o ensino fundamental entre estados e municípios se torna efetiva através da lei de no 9394/96, a Lei de Diretrizes e Bases da Educação Nacional, e da Emenda Constitucional 14/96, já que se caracteriza por concretizar o redimensionamento dos recursos para o ensino por meio da criação do Fundo de 
Acompanhamento Público dos Investimentos em Educação em Viçosa/MG

Manutenção e Desenvolvimento do Ensino Fundamental e Valorização do Magistério, o FUNDEF (BRASIL, 1996). Foi estabelecido pela CF de 1988, através do Art. 211, II que: "Os Municípios atuarão prioritariamente no ensino fundamental e na educação infantil".

Da mesma forma, com a CF88, a União foi obrigada a aplicar no mínimo $18 \%$ de suas receitas de impostos e os Estados, Distrito Federal e os Municípios no mínimo 25\% para a Manutenção e Desenvolvimento do Ensino (MDE) e o Salário Educação continuou a ser fonte de contribuição social ao financiamento educacional.

Mesmo com o aumento da obrigação do município de colocar $25 \%$ de sua receita, incluídas as transferências, na expansão e desenvolvimento do ensino, não resolve o problema de financiamento da educação básica, dada a profunda desigualdade entre os municípios brasileiros (MELLO, 1988, p. 53).

A subvinculação de recursos, conforme Duarte e Faria (2010), passou a acontecer a partir da Emenda Constitucional $n^{\circ}$ 14/96, que introduziu uma mudança na estrutura do financiamento do ensino fundamental público no País. A partir dessa Emenda, $60 \%$ dos $25 \%$ dos recursos destinados à MDE, ou seja, $15 \%$ desses impostos foram destinados ao Ensino Fundamental, através de um fundo de natureza contábil - FUNDEF, cuja efetivação se deu mediante sistema de contas bancárias.

Segundo Bueno e Pergher (2016), o financiamento da educação pública vem se implementando no Brasil, após o FUNDEF, por meio de fundos para a educação, considerando os percentuais em prol da MDE, já citados. Os artigos 70 e 71 da LDB n 9.394 estabelecem quais as despesas que podem ou não ser consideradas como MDE

Art. 70. Considerar-se-ão como de manutenção e desenvolvimento do ensino as despesas realizadas com vistas à consecução dos objetivos básicos das instituições educacionais de todos os níveis, compreendendo as que se destinam a:

I - remuneração e aperfeiçoamento do pessoal docente e demais profissionais da educação;

II - aquisição, manutenção, construção e conservação de instalações e equipamentos necessários ao ensino;

III - uso e manutenção de bens e serviços vinculados ao ensino;

IV - levantamentos estatísticos, estudos e pesquisas visando precipuamente ao aprimoramento da qualidade e à expansão do ensino;

$\checkmark$ - realização de atividades-meio necessárias ao funcionamento dos sistemas de ensino;

$\mathrm{VI}$ - concessão de bolsas de estudo a alunos de escolas públicas e privadas;

VII - amortização e custeio de operações de crédito destinadas a atender ao disposto nos incisos deste artigo;

VIII- aquisição de material didático-escolar e manutenção de programas de transporte escolar.

Art. 71. Não constituirão despesas de manutenção e desenvolvimento do ensino aquelas realizadas com:

I - pesquisa, quando não vinculada às instituições de ensino, ou, quando efetivada fora dos sistemas de ensino, que não vise, precipuamente, ao aprimoramento de sua qualidade ou à sua expansão;

II - subvenção a instituições públicas ou privadas de caráter assistencial, desportivo ou cultural;

III - formação de quadros especiais para a administração pública, sejam militares ou civis, inclusive diplomáticos; 
Acompanhamento Público dos Investimentos em Educação em Viçosa/MG

IV - programas suplementares de alimentação, assistência médico-odontológica, farmacêutica e psicológica, e outras formas de assistência social;

$V$ - obras de infraestrutura, ainda que realizadas para beneficiar direta ou indiretamente a rede escolar;

$\mathrm{VI}$ - pessoal docente e demais trabalhadores da educação, quando em desvio de função ou em atividade alheia à manutenção e desenvolvimento do ensino.

O FUNDEF foi instituído em 12/09/1996, segundo Bueno e Pergher (2016), através da Emenda Constitucional $n^{\circ} 14$, e regulamentado pela Lei 9.424 de 24/12/96, por dez anos, no âmbito de cada estado e município. Dessa forma, como já visto, os municípios passaram a ter maiores responsabilidades com a destinação de recursos para a educação, dada a vinculação de um percentual da receita para essa pasta.

O montante arrecadado era redistribuído entre as escolas de ensino fundamental público de acordo com o número de alunos que constavam no censo escolar do ano anterior, e cabia à União a complementação quando o valor mínimo aluno não era atingido.

Mello (1988) afirma que a ampliação do acesso ao ensino fundamental foi obtida para as crianças dos 7 aos 14 anos, já que foram investidos recursos excepcionais no setor, impactando positivamente na universalização desse nível de ensino. Mas, ao se dar atenção especial ao ensino fundamental, outros segmentos foram relegados, principalmente as redes municipais com relação à educação infantil e à educação de jovens e adultos e, na rede estadual, o ensino médio. Ou seja, o FUNDEF estava restrito ao ensino fundamental, sendo que os outros níveis da educação básica também necessitavam de investimentos para o alcance das metas para o setor. Assim, embora o governo federal assuma a responsabilidade legal de direcionar maiores recursos para a educação básica, o FUNDEF tem como foco o ensino fundamental.

Para fazer frente a essa situação, implementou-se, então, o Fundo de Manutenção e Desenvolvimento da Educação Básica e de Valorização dos Profissionais da Educação (FUNDEB), que tem os mesmos objetivos expressos para o FUNDEF e os mesmos percentuais de vinculação de recursos, porém estendendo-se a toda a educação básica e às diversas modalidades de ensino, que inclui, segundo Oliveira (2008), além do ensino fundamental, a Educação de Jovens e Adultos, a Educação indígena e Quilombola, a Educação Infantil e o Ensino Médio. Também como o FUNDEF, o FUNDEB é um fundo provisório, com duração prevista de 14 anos, sendo que, durante a sua vigência, os estados, os municípios e o Distrito Federal deverão investir os recursos em MDE da educação básica e na remuneração de seus profissionais (PINTO; ADRIÃO, 2006).

Segundo Duarte e Faria (2010), a arrecadação de impostos foi ampliada, sendo que as mudanças mais significativas da passagem do FUNDEF para o FUNDEB foram: incremento de novos impostos que antes não faziam parte do FUNDEF como: Incidentes sobre rendimento pagos pelos estados e municípios (IRRF); ITR; ITCM e o IPVA, sendo $20 \%$ ao longo de quatro anos dependendo do imposto.

O processo de descentralização e municipalização no Brasil tem sofrido as consequências "de uma racionalidade econômico-financeira excludente" (SOUZA; FARIA, 2004, p. 936). Não obstante o reconhecimento de que tal movimento não teve a intenção de democratizar a ação pública, fica clara a viabilização de um caminho que pode impedir a verdadeira democratização e organização na gestão municipal da educação. Alguns estudos 
Acompanhamento Público dos Investimentos em Educação em Viçosa/MG

apontam até mesmo a sinalização de uma tendência de privatização, além da crescente tensão em torno da ausência de verdadeira autonomia e emancipação dos municípios.

\section{Democratização do Ensino e Gestão Democrática}

De acordo com Gadotti (2001), os entraves acerca da democratização da educação pública e de qualidade fizeram parte de diversos setores da sociedade, há algumas décadas, mas esse embate se intensificou a partir da década de 1980, consolidando o princípio da gestão democrática, através do art. 206 da CF88. Por intermédio de leis complementares, a CF88 garantiu, como princípios para a educação brasileira, a obrigatoriedade, a gratuidade, a igualdade e a gestão democrática. O art. 214 da CF88 dispõe sobre a elaboração do Plano Nacional de Educação (PNE), no qual resguarda também a gestão democrática.

A LDB 9394/96 determina, em seu art. 3ㅇ que a gestão democrática do ensino público é um princípio fundamental para a garantia de uma educação de qualidade. Mais adiante, no art. 14, define que também no âmbito das escolas esse princípio deve ser respeitado e garantido pela via da participação da comunidade escolar e dos profissionais da educação, organizados em conselhos escolares ou equivalentes.

Esse pressuposto, que nasce com a CF88 e se adensa com a publicação da LBD, apresentou um rumo para os sistemas de ensino, mas não estabeleceu diretrizes para que os dirigentes municipais implementem ações efetivas visando a gestão democrática, apenas fez clara a premissa lógica de que deve haver participação de todos os envolvidos nos processos decisórios.

No entanto, Gadotti (2001) adverte que de nada adianta a prescrição de uma Lei de Gestão Democrática do Ensino Público, que concede autonomia pedagógica, administrativa e financeira às escolas, se o gestor, os professores, os alunos e demais atores do processo desconhecem o significado político da autonomia. Extrapolando para o âmbito do município, de nada adianta instituir tal lei se não há participação social nos conselhos que se prestam a fiscalizar, e a exercer sua função consultiva e deliberativa de assessoria ao prefeito, se os conselheiros desconhecerem seu papel e a importância das ações oriundas desses órgãos para a garantia do direito à educação pública, justa e democrática.

Os primeiros conselhos de educação, segundo Bordignon (2009), foram criados com base na referência dos conselhos ingleses, admitindo a função de conselhos determinantes e deliberativos das empresas para a gestão do ministério ou secretaria a que se vinculavam. Simplesmente assistiam ao governo e exerciam o seu papel em nome dele. Os conselhos brasileiros de educação datam ao Império, dois conselhos, um estadual e outro municipal. A Constituição de 1988 foi responsável, depois de criar os sistemas municipais de educação, por impulsionar a criação de conselhos municipais de educação com as atribuições específicas. Por conseguinte

A efetivação da gestão democrática da educação encontra nos conselhos, órgãos de representatividade social e deliberação plural, espaço privilegiado para estabelecer o contraponto da deliberação singular do executivo. Na sua origem, os conselhos de educação foram concebidos como órgãos de assessoramento superior, de caráter eminentemente técnico. Hoje assumem uma dimensão política (BORDIGNON, 2009, p. 53).

Os princípios norteadores da gestão democrática, quais sejam a autonomia, a participação e a transparência, foram se estabelecendo historicamente, à medida que 
Acompanhamento Público dos Investimentos em Educação em Viçosa/MG

avançavam as lutas em prol de uma educação pública para todos. De acordo com o Ministério da Educação (2004, p. 13), a história dos conselhos data de tempos bem remotos:

\begin{abstract}
Há quase três milênios, eles já existiam entre os povos hebreus, como forma primitiva de gestão entre grupos sociais. A bíblia também registra que Moisés reunia-se com os conselhos dos anciãos sábios para ajudá-lo no governo de seu povo. Estes conselhos de anciãos foram substituídos por conselhos de 'Beneméritos', que eram os homens mais sábios e bons.
\end{abstract}

Isto posto, percebe-se que a participação social nos mais diversos tipos de conselhos sempre foi uma estratégia para as decisões necessárias à convivência em sociedade, tanto para arbitrar sobre os limites dos direitos e deveres, quanto para cuidar do bem comum.

Barbosa e Lima (2010, p. 20) alertam que é papel dos conselhos, enquanto "instrumentos de controle social de alta relevância", reivindicar da gestão pública a divulgação de todas as ações e, "[...] desse modo, informar e convocar a população para participar diretamente da gestão de políticas públicas educativas".

Sabemos da dificuldade de muitos municípios para compor tais conselhos, justamente pela falta de pessoas interessadas em tornar-se conselheiros, o que faz com que muitos conselhos sejam formados, também, por indicados políticos que vão apenas sancionar os atos do poder executivo, uma vez que não é tarefa fácil recrutar conselheiros, como afirma a Série Mídia e Mobilização Social (2005, p. 24):

[...] o modelo de governança democrática instituído nos municípios brasileiros é incompleto. Embora apresente canais de interação entre governo e sociedade sobretudo em torno dos Conselhos Municipais disseminados -, mantém-se caracterizado por profundas desigualdades sociais, que reproduzem graves restrições à ampla inclusão e baixo grau de participação social. Para enfrentar os dilemas da reforma municipal brasileira é necessário que se insira no centro do debate a questão democrática.

Para a efetiva gestão democrática dentro do ambiente escolar e também dos sistemas de ensino, deve haver envolvimento da comunidade escolar e também o financiamento adequado por parte do poder público. E é justamente pela necessidade de observar como tem ocorrido a participação social nos Conselhos no âmbito dos municípios que nos interessamos neste trabalho.

Assim, o objetivo geral da pesquisa foi analisar como tem sido feito o acompanhamento e o controle público dos investimentos em educação em Viçosa, a partir da atuação dos conselhos (Conselho Municipal de Educação, do FUNDEB e de Políticas Públicas). Buscamos especificamente identificar como funciona a estrutura de financiamento (formas de transferências, alocação e destinação de recursos) da educação no contexto das finanças públicas municipais em biografia sobre o tema e em sites oficiais; averiguar como estão sendo destinados os recursos oriundos de impostos arrecadados pelo município para a pasta da educação; e mapear o trabalho de fiscalização e acompanhamento desenvolvido pelos conselhos atuantes no município, a partir das pautas e atas de reuniões, e da participação em reuniões com pautas específicas sobre a temática do financiamento em 2018. 
Acompanhamento Público dos Investimentos em Educação em Viçosa/MG

\section{Metodologia}

O estudo foi realizado a partir de participações em quinze (15) reuniões com pautas específicas sobre a temática do financiamento, ao longo do ano de 2018 , dos conselhos da cidade de Viçosa-MG, nas quais foi feito o uso de um diário de campo e de um gravador de voz: Conselho Municipal de Educação, Conselho Municipal do FUNDEB e o Conselho Municipal de Políticas Públicas. As reuniões ordinárias aconteciam mensalmente e contavam com a participação dos conselheiros, que são os representantes da sociedade civil e, também, do poder público.

Dessas 15 reuniões, 6 foram do Conselho Municipal de Educação, 5 do Conselho Municipal de Políticas Públicas e 4 do Conselho Municipal do FUNDEB. Foi utilizado, também, o levantamento das atas e pautas das reuniões anteriores do Conselho Municipal do FUNDEB (único Conselho que dispunha desse material acumulado), referentes ao ano de 2017, para o mapeamento do trabalho de fiscalização e acompanhamento desenvolvido por esse Conselho, visando a identificação das suas funções e as ações sob sua incumbência.

O tratamento e a análise dos dados foram feitos de acordo com o método dialético, visto que esse método "[...] requer o estudo da realidade em seu movimento, analisando as partes em constante relação com a totalidade" (OLIVEIRA, 2016, p. 53). Isso significa dizer que é preciso ter uma perspectiva sistêmica e holística da realidade, desenvolvendo análises que relacionem o contexto local com o nacional e o internacional. Ou seja, tratando da política de financiamento da educação em Viçosa, sem desconsiderar o contexto que se apresenta na política nacional e internacional sobre esse tema tão importante para a garantia de uma educação pública de qualidade.

\section{Resultados e Discussão}

\section{Análise das Reuniões dos Conselhos}

A primeira percepção ao iniciarmos nossa participação nas reuniões foi a de que havia uma certa desorganização quanto às reuniões e necessidades de cada Conselho. A maioria dos encontros começava com atrasos, o que fazia com que as reuniões ordinárias direcionassem outras extraordinárias, visto que o tempo dificilmente era suficiente para a discussão de tantas demandas.

Entretanto, observamos que é preciso relevar e ajustar com tranquilidade essas condutas, já que, quando os conselheiros precisam se reunir, há dificuldade para encontrar um horário em comum, devido às suas ocupações diárias. Ou seja, o conselheiro precisa deixar o seu local de trabalho para participar de uma reunião, e nem sempre isso é possível ou ocorre dentro do horário previsto. Foi possível identificar que o município não oferece os meios necessários para viabilizar tal participação, pois nem um espaço físico adequado para as reuniões foi providenciado até o momento.

Consideramos que, para o bom funcionamento de um Conselho, é essencial uma regularidade das reuniões que devem ocorrer no mínimo uma vez ao mês. É necessário um local fixo para os encontros, que seja restrito para os Conselhos do município, que ao todo somam atualmente vinte e três (23), não apenas do campo educacional, com a previsão de um(a) secretário(a) próprio(a) para fazer as atas e organizar os arquivos. 
Acompanhamento Público dos Investimentos em Educação em Viçosa/MG

Outro aspecto observado diz respeito à disponibilização das pautas, que, por vezes, são apresentadas um pouco antes do horário da reunião, o que nos obrigou a participar de todas as reuniões na incerteza de versarem ou não sobre financiamento educacional, que é o foco da pesquisa. Ressalta-se que, pelas regras vigentes, as convocações para as reuniões devem ser encaminhadas aos conselheiros com, pelo menos, 48 horas de antecedência, sendo formalizadas para que tenham legitimidade. Com tantas atribuições e na ausência de um(a) secretário(a), era comum que essas convocações não fossem enviadas dentro do prazo regulamentar.

Foi possível observar, igualmente, que é muito difícil recrutar voluntários no município, sendo que os poucos que se apresentam são profissionais e pais que se preocupam com os rumos da educação no município, e, muitas vezes, o mesmo conselheiro participa de mais de um Conselho. No entanto

O critério corrente hoje, a partir de sua adoção pelo Conselho Nacional de Educação (CNE) de 1995, é o da composição paritária: metade dos conselheiros de livre indicação do governo e metade indicados pela sociedade civil, por meio de suas entidades organizadas (BORDIGNON, 2009, p. 70).

Os conselheiros, além de serem voluntários, lidam com a dificuldade de não serem dispensados, por algumas vezes, do trabalho para se dedicarem a tal atividade, ou seja, a atuação como conselheiro representa uma ocupação extra. Portanto, consideramos ser necessário relativizar as exigências sociais que são feitas sobre os conselheiros, pelo encaminhamento de algumas decisões, já que, além de serem voluntários, não dispõem de uma diminuição da carga horária de trabalho para que possam participar das reuniões.

Os conselheiros da cidade de Viçosa não são indicados políticos, salvo pela secretária municipal de Educação. O tempo médio do mandato tem sido entre 2 e 4 anos, com direito a uma recondução. São pessoas da comunidade escolar que realmente querem participar das discussões, o que muitas vezes ficou evidenciado nos discursos de indignação que proferiam quando o poder legislativo local tomava decisões à revelia dos Conselhos, deslegitimando-os enquanto instância consultiva e deliberativa.

Em relação às atas dos anos anteriores, o único Conselho que as apresentou foi o do FUNDEB, pois a falta de um profissional para secretariar as reuniões inviabilizou por anos a elaboração e o arquivamento dessa documentação. O Conselho do FUNDEB apresentou algumas atas do ano de 2017, porque a presidente desse conselho está nessa posição há alguns anos e, por vontade pessoal, foi fazendo tal registro, ainda assim sem uma regularidade adequada. Os demais Conselhos não apresentaram atas dos anos anteriores, porém, a partir do ano de 2018 a Secretaria Municipal de Educação disponibilizou uma funcionária para secretariar as reuniões e esta começou a formalizar as pautas e deliberações que foram debatidas pelo Conselho Municipal de Educação, pelo Conselho de Políticas Públicas e pelo Conselho do FUNDEB.

A falta dessa documentação dificultou nosso trabalho de análise das atividades dos Conselhos em anos anteriores, comprometendo, também, o acesso público a informações relevantes para o campo educacional. Além disso, outro fator dificultador foi o acesso aos dados, porque, após a nossa solicitação, os presidentes demoravam muito tempo para nos encaminhar os documentos. 
Acompanhamento Público dos Investimentos em Educação em Viçosa/MG

Identificamos que muitas informações importantes e decisões coletivas estão registradas nas memórias dos conselheiros que atuam há mais tempo, e, caso estas pessoas se afastem, os dados certamente se perderão. Portanto, nossa pesquisa evidencia a necessidade de o município privilegiar os Conselhos como instâncias deliberativas e consultivas fundamentais para o controle dos gastos públicos e também das decisões políticas do campo educacional, organizando um espaço adequado para reuniões e arquivos, e disponibilizando profissionais de suporte para atender às demandas de todos os Conselhos, não apenas àqueles voltados para a educação.

O Conselho de Políticas Públicas tem atuação muito recente, atendendo a uma normativa do ano de 2017 do governo do estado, que demandou dos municípios a necessidade da sua criação imediata. Tal Conselho foi criado a partir da atuação de representantes dos outros Conselhos já existentes, sem que houvesse uma formação para tal, prejudicando a compreensão dos conselheiros em relação às suas especificidades. Os problemas já apresentados anteriormente sobre os demais conselhos se repetem de forma ainda mais acentuada no Conselho de Políticas Públicas. As possíveis causas estão relacionadas ao seu pouco tempo de atuação. Como os conselheiros não estavam habituados com a legislação e não tiveram um treinamento para a atuação nesse Conselho, foi observado que as reuniões seguem um padrão já instituído em outros Conselhos, sem grandes mudanças, o que inicialmente acabou parecendo um trabalho repetitivo e sem uma função clara definida. Esse Conselho está, aos poucos, encontrando as orientações adequadas para prosseguir com o trabalho de acordo com a sua competência e especificidade.

Desta forma, identificamos que a participação do governo, quer seja no âmbito estadual ou municipal, no processo de formação dos conselheiros é inócua, e sugerimos que haja maior participação e ação governamental antes e durante a instituição dos Conselhos, de modo a capacitar os sujeitos que se dispõem a, justamente, fiscalizar a ação dos entes públicos e zelar pela qualidade do ensino oferecido às crianças e jovens do município, pois só instituir o Conselho e esperar que a população dê conta disso sem prepará-la é um retrocesso que limita o alcance das ações dos conselheiros.

Como já observamos, a atuação dos Conselhos é recente no País e ainda precisa instituir-se como uma cultura de participação política eficaz na luta pelo direito a uma educação de qualidade. É necessário

[...] que a criação do conselho represente a vontade política da sociedade e não uma mera formalidade legal. Por isso, o processo de criação do conselho é mais importante do que a qualidade final da lei. O perfil do conselho, sua organização, composição, funções e atribuições devem resultar de ampla discussão na comunidade (BORDIGNON, 2009, p. 53).

Quanto à questão do financiamento, nenhum dos Conselhos investigados, a não ser o Conselho do FUNDEB, discute diretamente sobre a temática, mas há interlocuções importantes e necessárias, porque as denúncias que muitas vezes chegam até o Conselho Municipal de Educação e ao Conselho de Políticas Públicas passam pela inadequação da aplicação dos recursos orçamentários.

Os Conselhos são uma prerrogativa importante para o exercício da cidadania e podem ser classificados de acordo com as funções que eles exercem, podendo ter as funções de: fiscalização, mobilização, deliberação ou de consultoria. De acordo com Bordignon (2009), a 
Acompanhamento Público dos Investimentos em Educação em Viçosa/MG

função fiscalizadora tem por objetivo acompanhar e controlar as ações tomadas pelos governantes. A mobilizadora pressupõe o incentivo à participação popular na gestão pública e à satisfação para com a sociedade acerca das políticas públicas. A deliberativa refere-se ao poder atribuído ao conselho de decisão final em matérias específicas de sua competência; e a consultiva serve para gerar opiniões e/ou sugestões formais sobre diversos assuntos correlatados.

Em relação ao cadastro dos conselheiros, há um prazo estabelecido para este, já que as portarias têm um prazo definido, como um mandato. Quando o presidente for um servidor do quadro efetivo da Secretaria Municipal de Educação, deverá ser assegurada na lei a liberação para a participação das reuniões (CONTROLADORIA GERAL DA UNIÃO, 2012).

Cabe destacar que, apesar de o município não ter um sistema de ensino próprio, o Conselho Municipal de Educação possui caráter deliberativo, de acordo com a lei municipal n. 2035/2010: "Art. 2. O Conselho Municipal de Educação exercerá as funções de caráter normativo, consultivo e deliberativo sobre a formulação e o planejamento das políticas educacionais do município". Essa é uma conquista muito importante para aqueles que exercem e/ou exercerão a função de conselheiros, e também acarreta maior responsabilidade, tendo em vista que as deliberações desse ator social, tão necessário para o acompanhamento e controle dos investimentos públicos em educação, deverão ser acolhidas pelos entes públicos.

Como já exposto, os Conselhos são de suma importância para o acompanhamento e controle dos recursos dos Fundos, porque pelo acompanhamento constante são capazes de mostrar as falhas existentes na aplicação da legislação. Consequentemente

[...] o exercício da presidência pelo secretário de educação ou por alguém por ele indicado traz desvantagens para ambos os lados. Além dos inevitáveis constrangimentos de posição em eventuais conflitos, elimina a instância democrática de negociação desses conflitos (BORDIGNON, 2009, p. 84).

Em Viçosa, nenhum dos Conselhos analisados é presidido pela secretária municipal de Educação, mas sim por um representante da comunidade escolar.

Os Conselhos mais organizados e atuantes conseguem interferir mais nas políticas públicas. Esses devem ter um regimento interno que defina seus procedimentos, sua estrutura e a periodicidade de suas reuniões. A maioria se reúne mensalmente e seus encontros são abertos à população. Embora essa regra seja pouco divulgada, é importante para permitir o acompanhamento das decisões, especialmente no que diz respeito à aplicação dos recursos do fundo, quando referente ao FUNDEB. O Conselho

[...] exerce o cuidado do projeto educativo fundamentado na cidadania, na nacionalidade, que requer visão geral do todo social, construída pelos diferentes segmentos sociais. $O$ interesse coletivo se situa acima e além dos interesses singulares das categorias (BORDIGNON, 2009, p. 71).

O foco deve ser afirmar o interesse do todo, em detrimento do interesse das partes, promovendo a justiça social e a equidade.

Por fim, no que diz respeito à equipe de conselheiros analisada nessa pesquisa, um problema comum à maioria é a capacitação, como já observamos, tendo em vista que as formações são buscadas individualmente pelos conselheiros e muitos passam a compreender 
Acompanhamento Público dos Investimentos em Educação em Viçosa/MG

o seu papel a partir do momento em que começam a participar das reuniões e ações do Conselho. O trabalho nos Conselhos exige, por um lado, conhecimento da legislação e da dinâmica das políticas da área e, por outro, preparo para lidar com planejamento e gestão. Muitos dos próprios conselheiros reconhecem que suas experiências com esses temas são insuficientes, mas nosso contato com a realidade dos Conselhos de Viçosa nos mostrou que é possível aprender com o próprio trabalho que realizam a partir da experiência de outros conselheiros. Entendemos que o ideal é haver uma capacitação inicial, por parte do governo, sempre que um conselheiro assume essa importante tarefa, e que a formação continuada, em contato com outros conselheiros, contribui para imprimir mais qualidade ao trabalho que exercem.

Apesar de não ser tarefa fácil recrutar conselheiros para os diversos Conselhos que fiscalizam os gastos em educação, atualmente todos os Conselhos de Viçosa se encontram em funcionamento e contam com a participação de conselheiros representantes da comunidade escolar como professores, funcionários e pais/familiares dos estudantes.

Ressaltamos que estava prevista, também, a participação da aluna pesquisadora nas reuniões do Conselho Municipal de Alimentação Escolar, entretanto, os horários das reuniões conflitaram com os horários de aulas. Essas reuniões sempre aconteciam nas primeiras quintas-feiras de cada mês, sem possibilidade de mudança, pois os dias e horários foram estabelecidos no início do ano para melhor atender aos conselheiros.

Aprendemos, como elucidado acima, que recrutar conselheiros não é tarefa fácil e os que se apresentam são pessoas que há anos desempenham o papel de representação social, como a presidente do Conselho do FUNDEB, que está à frente da presidência há mais de dez anos e que já manifestou o desejo de se afastar do cargo. Como ainda não encontrou ninguém capacitado e apto, já que o exercício desse cargo exige conhecimentos da área, ela se mantém ativa.

Compreender as atas dos anos anteriores, que estavam mal escritas (semântica e sintaticamente); participar das reuniões em salas quentes e pequenas; fazer o deslocamento para as reuniões que aconteciam em diversos locais da cidade de Viçosa; e manter um diálogo presencial com os conselheiros (devido ao fato de serem pessoas com diversas ocupações diárias), foram situações desafiadoras para a realização dessa pesquisa.

\section{Análise das Atas e Pautas das reuniões do Conselhos}

Em relação às atas e pautas das reuniões passadas do Conselho Municipal do FUNDEB, relativas ao ano de 2017, foi possível perceber que foram discutidas questões como: prestação de contas, transporte escolar, valores dos repasses mensais do FUNDEB e questionamentos à secretaria de finanças. Tais pautas se mantiveram frequentes também nas reuniões das quais participamos no ano de 2018. Com base no caderno de atas ao qual pudemos ter acesso, foram realizadas 5 reuniões ao longo do ano de 2017.

Todas as reuniões do conselho ocorreram na Secretaria Municipal de Educação, estando presente a presidente do conselho, o representante dos professores, a representante dos servidores técnico-administrativos, o representante do Conselho Municipal de Educação, a representante do Conselho Tutelar, a secretária municipal de finanças, a Coordenadora Pedagógica do Ensino Fundamental do município, a Chefe do Departamento de Educação 
Acompanhamento Público dos Investimentos em Educação em Viçosa/MG

Infantil da Universidade Federal de Viçosa, a chefe do Departamento de Administração e Controle e a secretária municipal de Educação.

Permearam questionamentos da presidente do Conselho à Secretaria de Finanças em relação aos investimentos em educação, e a secretária teceu comentários sobre os altos gastos da administração em relação ao repasse para a manutenção da câmara de vereadores, que consome mais de $R \$ 500.000,00$ ao mês, e também o repasse para manutenção do Instituto de Previdência dos Servidores Efetivos (IPREVI). Todas essas despesas fazem com que se reduzam os investimentos em diversas áreas, inclusive na educação.

Outras demandas diziam respeito ao valor custo aluno para o exercício de 2017. Segundo a presidente do Conselho, o recurso para a educação ainda é pouco e precisa de melhorias. A secretária de Finanças elucidou que:

Não há condições de ter reajuste de salário do quadro de profissionais da educação, porque até o momento, os recursos não eram suficientes. Os recursos para a educação correspondem a $31 \%$, sendo que o repasse obrigatório é de $25 \%$. O transporte escolar é um gasto que deve ser revisto, em relação ao pagamento de transporte para os alunos da rede estadual de ensino (ATA FUNDEB, 2017).

Ainda sobre o transporte escolar, a presidente do Conselho atentou para o fato de que a lei Municipal que determina que o município deve ser responsável pelos gastos do transporte da Rede Estadual de Ensino precisa ser modificada.

Como elucidado anteriormente, as questões debatidas nas pautas das reuniões de 2017 perpassaram as de 2018. De acordo com a presidente, dos recursos que o município recebe, a maior parte é comprometida com o pagamento do pessoal e encargos sociais, e, em segundo lugar, com o transporte escolar. Em uma das reuniões, a presidente esclareceu que o recurso que vem do estado para o transporte escolar é o destinado apenas ao transporte escolar rural, mas o transporte é utilizado também para transportar alunos do estado. $O$ gasto com o transporte é uma questão grave, já que é encargo também do estado e não apenas do município.

Cabe ressaltar que, após inúmeros debates nos Conselhos dos quais participamos, e da atuação de seus conselheiros junto ao Poder Legislativo de Viçosa, no ano de 2018 foi aprovada a lei $n^{\circ} 2728 / 2018$, que dispõe sobre a alteração e consolidação da legislação municipal que trata do transporte escolar gratuito aos alunos da rede pública municipal de ensino. Ainda são evidenciadas outras providências, visando, com isso, reduzir os gastos desse ente administrativo e responsabilizar o estado pelos necessários repasses referentes aos alunos da rede estadual.

Por vezes, a presidente esclareceu sobre a importância da prestação de contas e da funcionalidade do FUNDEB, que é o pagamento dos profissionais da educação, bem como dos encargos sociais. Foram vistas irregularidades nos planos de trabalho e na prestação de contas das creches filantrópicas, pois estas não conseguiam atender às exigências para a criação de convênio. Alguns aspectos muito debatidos foram a prestação de contas de uma escola, que não foi aprovada e estava irregular, assim como o pagamento de professores com cheque e a compra de bilhetes de estacionamento com o dinheiro do FUNDEB (pagamento de funcionários que trabalhavam no rotativo do estacionamento). 
Acompanhamento Público dos Investimentos em Educação em Viçosa/MG

Em uma das reuniões na qual foi discutida a destinação de recurso do FUNDEB, a presidente relatou que o valor do FUNDEB para as creches filantrópicas é calculado como se estas fossem da rede regular, sendo que o mesmo valor que é repassado ao município é repassado a elas. O recurso do FUNDEB varia de acordo com a jornada (parcial ou integral) e o valor-aluno deveria ser de $\mathrm{R} \$ 300,00$ para as entidades filantrópicas, para que possam atender um maior número de alunos.

A questão das creches conveniadas também foi discutida pelo Conselho Municipal de Educação em 2018. Foi elaborado e apresentado um projeto de Resolução à Câmara dos Vereadores da cidade, ainda em 2017, relativo à organização da estrutura e do funcionamento da educação infantil no município. Para elaborar esse projeto, participaram de algumas reuniões os representantes dos Conselhos de educação, representantes das creches públicas, particulares e filantrópicas de Viçosa, e representantes da Secretaria Municipal de Educação. Desse trabalho foi publicada a Resolução da Secretaria Municipal de Educação $n^{\circ}$ 001/2017, que regulamentou as atividades referentes ao atendimento à educação infantil no município.

A resolução apresenta um conjunto de diretrizes que norteiam os "Planos de trabalho" que as escolas devem fazer. Sendo assim, todas as creches deveriam absorver tais diretrizes em seu Projeto Político Pedagógico (PPP) para serem consideradas aptas ao convênio. Observa-se que, como atualmente o município não tem recursos suficientes para construir creches em todos os bairros e atender integralmente a demanda por educação infantil, ele conta com o apoio das creches filantrópicas, que, portanto, passam a ser conveniadas e a ter direito de receber o repasse do FUNDEB e do subsídio da prefeitura.

$\mathrm{Na}$ mesma reunião, do dia 24/04/18, foram debatidas as questões de se incluir na Resolução n 001/2017 uma parte que está sendo normatizada por outra Resolução, "a Resolução do Cadastro Escolar", com as ideias centrais. Outro ponto foi o artigo 15 do parágrafo 3, que versava sobre a infrequência, pois esta não poderá resultar em retenção da criança atendida pelas creches, nem gerar a perda do direito à vaga, mas uma punição no sentido de não ser assegurada a vaga no tempo integral, pois não é justo com as outras famílias que valorizam a vaga do filho e que fazem jus a ela. Essa situação atingiria as crianças que excedessem os $40 \%$ de falta, que perderiam o direito de matrícula no tempo integral e seriam remanejadas para o parcial. Concluíram, ao final, que deveria haver uma "punição" temporária como tirar a criança do tempo integral para o parcial, perdendo o direito no respectivo ano e já no ano seguinte a família passaria a ter a opção novamente da matrícula no integral.

Quanto ao Conselho de Políticas Públicas, surgiram debates acerca de os municípios terem que aplicar $25 \%$ de sua receita de impostos em educação. Essa aplicação é feita na forma de subvenção para as escolas regulares e também para as creches conveniadas. Até o ano de 2017 não havia uma regra clara em relação à distribuição desse recurso, mas ficou definido pelo Conselho que, a partir de 2018 , as creches receberiam um valor estipulado por aluno, a exemplo do que ocorre com o FUNDEB.

Essa regulamentação favoreceu as creches menores, que não dispunham de um apoio político capaz de fazer investidas junto ao Poder Público na hora de distribuição dos recursos, mas acabou reduzindo o valor do repasse feito para as creches que dispunham desse apoio, especialmente por parte de alguns vereadores do município. O Conselho de Políticas Públicas 
Acompanhamento Público dos Investimentos em Educação em Viçosa/MG

reforçou que a regulamentação desse repasse estava embasada pelos princípios da equidade e da justiça, tendo em vista que todas as crianças do município merecem tratamento igual, em termos de investimento, por parte do poder público.

Essa mudança na forma de repassar o subsídio foi informada a todas as instituições no ano de 2017, para passar a vigorar em 2018. Ainda assim, em 2018 uma instituição se sentiu prejudicada e envidou esforços junto aos entes públicos para ampliar o seu acesso à subvenção, e conseguiu um aporte adicional por parte do Poder Executivo local. Tal situação contrariou as regras estipuladas pelo Conselho, criou um constrangimento junto às outras instituições que não foram informadas sobre esse repasse extra e não foram consultadas, e fez com que o Conselho se reunisse diversas vezes para ouvir as partes envolvidas no intuito de se encontrar uma solução.

Esse episódio nos mostrou que, apesar da importância atribuída aos Conselhos atualmente como instâncias consultivas e deliberativas advindas da sociedade civil, há práticas políticas historicamente constituídas nos municípios que atravessam as ações dos conselheiros, fazendo com que o clientelismo e a pouca transparência com que é tratada a questão do financiamento no âmbito local ainda persistam.

Um dos conselheiros sempre enfatizava que ainda não há um olhar rigoroso de respeito ao orçamento da educação, sendo que este ainda atende a vontades políticas e isso deveria ser rompido, pois infelizmente as pessoas se apropriam dos recursos públicos como se fossem seus e o destinam para onde queiram, o que contraria todo o processo de controle público. Tal ação deslegitima o Conselho, já que, desse modo, bastaria uma conversa com o prefeito para se obter uma verba extra, um tema que no fim não passa por uma discussão no respectivo Conselho como deveria ocorrer.

Dessa forma, reforçamos a necessidade de formação para os conselheiros que são voluntários, para que estes assumam as responsabilidades dessa função cientes do seu poder de atuação, não se tornando vítimas de um sistema que pode ser patrimonialista. Consideramos, ainda, ser indispensável estabelecer punições justas em caso de não cumprimento das decisões dos conselhos por parte do poder público, para que eles possam realmente intervir e fiscalizar os investimentos em educação.

\section{Conclusões}

Analisamos como tem sido feito o acompanhamento e controle público dos investimentos em educação em Viçosa, a partir da atuação dos Conselhos (Municipal de Educação, Municipal do FUNDEB e de Políticas Públicas).

Como objetivos alcançados, identificamos como funciona a estrutura de financiamento (formas de transferências, alocação e destinação dos recursos) da educação no contexto das finanças públicas municipais em bibliografia sobre o tema e em sites oficiais, acompanhamos as reuniões dos conselhos ao longo do ano de 2018, e coletamos e analisamos as atas dos anos anteriores que tinham relação com a questão do financiamento.

Foi importante e desafiador realizar esta pesquisa por diversos motivos: pela identificação da precariedade em termos de organização que ainda sujeita os Conselhos a se encontrarem em vários locais, bem como a ausência de um funcionário que tenha como função secretariar as reuniões e cuidar da documentação relativa a elas; a dificuldade em 
Acompanhamento Público dos Investimentos em Educação em Viçosa/MG

conseguir conselheiros provenientes da sociedade civil; da mesma forma, foi observada a ausência de formação inicial e continuada para melhorar a atuação de tais conselheiros; o modelo político-histórico instituído pelo município, em razão do qual, muitas vezes, desconsideram-se as decisões dos conselhos; a disponibilização das pautas com a antecedência de 48 horas; dentre outros.

Ao longo da nossa participação nas reuniões dos Conselhos, foi possível perceber a importância dessa atuação da sociedade, pela natureza das pautas que se colocavam: aplicação dos recursos do FUNDEB, transporte escolar, denúncias de uso irregular de recursos da subvenção, alocação de recursos para as creches filantrópicas, dentre tantas outras questões cruciais para a manutenção e desenvolvimento do ensino de qualidade pelo município.

A tão necessária participação popular no controle dos gastos públicos precisa ainda superar o modelo de política que se pauta no apadrinhamento local, no apoio político a determinados grupos em detrimento de outros, pois se trata de atender com qualidade a todas as crianças do município. A profissionalização pela via da qualificação dos conselheiros é fundamental para garantir que cada vez mais cidadãos queiram participar e acompanhar de perto como o governo executa o orçamento advindo dos impostos, atendendo equitativamente a todos e cumprindo o princípio da gestão democrática da educação.

\section{Referências}

BARBOSA, G. F. de M; LIMA, Y. S. A participação dos Conselhos Municipais de Educação na gestão de recursos públicos: estudo de caso na cidade de João Pessoa/PB. In: SIMPÓSIO DE EXCELÊNCIA EM GESTÃO E TECNOLOGIA, 2010. Anais... 2010. Disponível em:<https://www.aedb.br/seget/arquivos/artigos16/21324209.pdf>. Acesso em: 14 dez. 2018.

BORDIGNON, G. Gestão da educação no município. Sistema, conselho e plano. São Paulo: Instituto Paulo Freire, 2009.

BRASIL. Constituição Federal. Diário Oficial da União, Brasília, 1988. Disponível em: <http://www.planalto.gov.br/ccivil_03/Constituicao/Constituicao.htm>. Acesso em: $11 \mathrm{dez} .2018$.

BRASIL. Ministério da Educação. Lei de Diretrizes e Bases da Educação Nacional. Lei n. 9394, de 20 de dezembro de 1996. Estabelece as diretrizes e bases da educação da educação nacional. Diário Oficial da União, Brasília, 1996.

BRASIL. Ministério da Educação. Secretaria de Educação Básica. Conselho escolar e o financiamento da educação no Brasil. 2004. Disponível em: <http://portal.mec.gov.br/seb/ arquivos/pdf/Consescol/cd\%207.pdf>. Acesso em: 10 dez. 2018.

BUENO, E.N.; PERGHER, C. J. Analisando a trajetória dos fatores de ponderação estabelecidos no FUNDEB: 2007 a 2016. In: FINEDUCA. FINANCIAMENTO DA EDUCAÇÃO NO BRASIL: AVANÇOS E IMPASSES, 2016, São Paulo. Anais... São Paulo, 2016. p. 65-83.

CONTROLADORIA GERAL DA UNIÃO. Controle social: orientações aos cidadãos para participação na gestão pública e exercício do controle social. Brasília, DF: Coleção Olho Vivo, 2012. 
Acompanhamento Público dos Investimentos em Educação em Viçosa/MG

DUARTE, Marisa R. T.; FARIA, Geniana Guimarães. Recursos públicos para escolas públicas: as políticas de financiamento da educação básica no Brasil e a regulação do sistema educacional federativo. Belo Horizonte: RHJ, 2010.

GADOTTI, Moacir. Concepção dialética da educação: um estudo introdutório. São Paulo: Cortez, 2001.

MELLO, Guiomar Namo de. A descentralização que vem do centro. Revista Educação Municipal, São Paulo, ano 1, n.1, jun. 1988.

OLIVEIRA, M. M. de. Como fazer pesquisa qualitativa. 7. ed. ver. e atual. Petrópolis: Vozes, 2016.

OLIVEIRA, R. Os limites do FUNDEB no financiamento do ensino médio. Currículo sem Fronteiras, v. 8, n. 2, p. 78-96, jul./dez. 2008.

PINTO, J. M. R.; ADRIÃO, T. Noções gerais sobre o financiamento da educação no Brasil. políticas públicas e financiamento da educação. EccoS - Revista científica, São Paulo, v. 8, n.1, p. 23-46, jan./jun. 2006.

SOUZA, D. B.; FARIA, L. C. M. Reforma do estado, descentralização e municipalização do ensino no Brasil: a gestão política dos sistemas públicos de ensino Pós-LDB 9.394/96. Ensaio: avaliação e políticas públicas em educação, Rio de Janeiro, v. 12, n. 45, p. 925-944, out./dez. 2004.

Renata Martins Pena é graduada no curso de Pedagogia pela Universidade Federal de Viçosa, em Minas Gerais. Atuou como monitora, em 2017, no Núcleo de Educação de Jovens e Adultos (NEAD). Em 2018, realizou pesquisa de Iniciação Científica financiada pela FAPEMIG.

ORCID: http://orcid.org/0000-0001-7035-8129

E-mail: renata.pena@ufv.br

Cristiane Aparecida Baquim é docente do Departamento de Educação da Universidade Federal de Viçosa, área de Gestão da Educação, subárea de Políticas Educacionais.

ORCID: http://orcid.org/0000-0002-5975-737X

E-mail: cbaquim@hotmail.com

Natália Rigueira Fernandes possui graduação em Pedagogia (2005) e Mestrado em Extensão Rural (2008) pela Universidade Federal de Viçosa. Atualmente é professora Assistente do Departamento de Educação da Universidade Federal de Viçosa

ORCID: http://orcid.org/0000-0002-7760-7981

E-mail: natalia.fernandes@ufv.br

Henrique Pinto Gomide é professor do departamento de Educação da Universidade Federal de Viçosa. Doutor em Psicologia pela Universidade Federal de Juiz de Fora (UFJF), com estágio sanduíche na University of Kansas Medical Center.

ORCID: http://orcid.org/0000-0001-7050-3971

E-mail: henrique.gomide@ufv.br

Recebido em 09 de maio de 2019

Aprovado em 20 de setembro de 2019 


\section{Editores do volume 10}

Márcia Aparecida Jacomini - Universidade Federal de São Paulo, Brasil

José Marcelino de Rezende Pinto - Universidade de São Paulo, Brasil

\section{Comitê Editorial}

Nalú Farenzena - Universidade Federal do Rio Grande do Sul, Brasil

Juca Gil - Universidade Federal do Rio Grande do Sul, Brasil

Theresa Adrião - Universidade Estadual de Campinas, Brasil

Ângelo Ricardo de Souza - Universidade Federal do Paraná, Brasil

\section{Conselho Editorial}

\section{Alejandro Morduchowicz}

Universidad Pedagógica, Provincia de Buenos Aires, Argentina

Andréa Barbosa Gouveia

Universidade Federal do Paraná, Brasil

Fernanda Saforcada

Universidade de Buenos Aires, Argentina

Jacques Velloso

Universidade de Brasília, Brasil

João Monlevade

Senado Federal, Brasil

Jorge Abrahão de Castro

Instituto de Pesquisa Econômica Aplicada / IPEA, Brasil

Lisete Regina Gomes Arelaro

Universidade de São Paulo, Brasil

Luis Carlos Sales

Universidade Federal do Piauí, Brasil

Luiz de Sousa Junior

Universidade Federal da Paraíba, Brasil

Luiz Fernandes Dourado

Universidade Federal de Goiás, Brasil

Magna França

Universidade Federal do Rio Grande do Norte, Brasil

Marcos Edgar Bassi

Universidade Federal de Santa Catarina, Brasil

Maria Angélica Pedra Minhoto

Universidade Federal de São Paulo, Brasil

Maria Beatriz Luce

Universidade Federal do Rio Grande do Sul, Brasil

Maria Dilnéia Espíndola Fernandes

Universidade Federal de Mato Grosso do Sul, Brasil

Nelson Cardoso do Amaral

Universidade Federal de Goiás, Brasil

Nicholas Davies

Universidade Federal Fluminense, Brasil

Robert E. Verhine

Universidade Federal da Bahia, Brasil

Romualdo Portela de Oliveira

Universidade de São Paulo, Brasil

Rosana Gemaque Rolim

Universidade Federal do Pará, Brasil

Rubens Barbosa de Camargo

Universidade de São Paulo, Brasil

Theresa Adrião

Universidade Estadual de Campinas, Brasil

Tristan McCowan

University of London, Reino Unido

Vera Jacob

Universidade Federal do Pará, Brasil

Vera Peroni

Universidade Federal do Rio Grande do Sul, Brasil

Vitor Henrique Paro

Universidade de São Paulo, Brasil

\section{Equipe editorial}

Apoio ao Comitê Editorial: Caio Cabral da Silva

Diagramação, Revisão de português e normalização: Edson Leonel de Oliveira

Revisão de inglês: Sabrina Ferreira

Fineduca - Revista de Financiamento da Educação

Associação Nacional de Pesquisa em

Financiamento da Educação

e-mail: revista.fineduca@gmail.com | site: http://seer.ufrgs.br/fineduca 